\title{
A VISÃO DOS PAIS SOBRE A ATUAÇÃO DA ESCOLA EM ASSUNTOS RELATIVOS À SEXUALIDADE
}

\author{
Andreia Freitas Zompero ${ }^{1}$ \\ Virginia lara Andrade Maistro² \\ Maria Conceição Costa Matos ${ }^{3}$
}

\begin{abstract}
RESUMO
O artigo tem como propósito verificar a visão dos pais dos alunos do sexto ano de um colégio estadual de um município brasileiro, referente às intervenções da escola, relacionadas às manifestações da sexualidade dos jovens estudantes. Trata-se de uma investigação de cunho qualitativo e para obtenção dos dados foram apresentadas quatro situações-problema para suscitar a reflexão dos participantes, utilizando-se de situações baseadas em fatos que ocorrem rotineiramente nos contextos escolares. As respostas foram separadas e analisadas em categorias. Os resultados apontam que os pais demonstram divergências sobre o que consideram uma intervenção ideal por parte da escola e receio quanto às formas de serem abordadas essas questões, além de considerarem que influenciarão no estímulo extemporâneo da sexualidade nos educandos. Constata-se que expõem receios e divergências sobre o enfoque da escola, na presença de cada caso, e que apresentam uma carência quanto à finalidade da educação sexual indicando a importância de levar para dentro do contexto escolar discussões e reflexões sobre os diversos temas que englobam a temática.
\end{abstract}

Palavras-chave: família; educação sexual; escola.

THE PARENTS' VISION ON THE SCHOOL'S ACTIVITIES IN SUBJECTS RELATED TO SEXUALIDADE

\section{ABSTRACT}

The article aims to verify the view of the parents of the sixth year students of a State College in a Brazilian municipality, regarding the school's interventions, related to the sexuality manifestations of the young students. It is a qualitative investigation and to obtain the data, four problem situations were presented to provoke the reflection of the participants, using situations based on facts that occur routinely in school contexts. The answers were separated and analyzed in categories. The results show that parents show disagreements about what they consider an ideal intervention by the school and fear about the ways to address these issues, in addition to considering that they will influence the extemporaneous stimulation of sexuality in students. It appears that they have fears and disagreements about the focus of the school, in the presence of each case, and that they have a lack as to the purpose of sex education, indicating the importance of taking discussions and reflections on the various themes within the school context. close the topic.

Keywords: family; sexual education; school.

Recebido em: $19 / 5 / 2020$

Aceito em: 29/9/2020

\footnotetext{
1 Autora correspondente. Universidade Estadual de Londrina - Jardim Portal de Versalhes 1. Londrina/PR, Brasil. CEP 86055-900. http:// lattes.cnpq.br/2231621376375299. https://orcid.org/0000-0002-5123-8073. andzomp@yahoo.com.br

2 Universidade Estadual de Londrina - UEL. Londrina/PR, Brasil. http://lattes.cnpq.br/4821476452100965. https://orcid.org/0000-0002-5172-6173

3 Secretaria de Educação do Estado do Paraná. Londrina/PR, Brasil. http://lattes.cnpq.br/9423846996253286. http://orcid.org/0000-0002-3917-5567
} 


\section{INTRODUÇÃO}

O cotidiano escolar traz diversos desafios, principalmente quanto ao convívio entre alunos e educadores, pois os papéis sociais diante do desenvolvimento pedagógico, por vezes, são relacionais e questiona-se o quanto este local está inteiramente preparado para trabalhar e dar conta de tanta complexidade que permeia essas relações humanas (FRANCO, 2016). Nessa convivência diária as manifestações da sexualidade emergem no comportamento e exteriorização dos alunos, o que exige dos educadores posicionamentos sobre estas questões, que muitas vezes não são compreendidos e apoiados pelos pais. De acordo com Figueiró (2009), estas manifestações revelam-se de diversas formas, seja por brincadeiras, falas, vestimentas, escritos nas paredes dos banheiros, nas carteiras ou até mesmo em situações como a gravidez precoce e agressividades de caráter sexual.

A incumbência de educar quanto à ética, moral, valores e inclusive para a sexualidade, é primordialmente da família, conforme Figueiró (2007). Pertence a ela a máxima responsabilidade na educação, no desenvolvimento e preparo para a vida dos seus fiIhos, uma vez que serve de exemplos e padrões a serem seguidos. Para muitos responsáveis, contudo, conversar com seus filhos sobre sexualidade gera muito desconforto e constrangimento e determinadas situações exigem intervenções imediatas, independentemente do preparo dos pais ou da escola. Mesmo, no entanto, sendo de responsabilidade dos pais a educação para a sexualidade, a escola também tem seu papel acerca da temática, uma vez que os jovens passam grande parte de seu tempo neste ambiente e é ela que detém o conhecimento científico para as suas demandas.

Durante a docência, por mais de 20 anos na Educação Básica, foi possível conviver com muitas adolescentes grávidas, algumas tiveram o apoio familiar na gestação, outras nem tanto; em alguns momentos a equipe escolar identificou uma série de casos de assédio ou de comportamentos sexuais descritos como inadequados pelos alunos.

Com o advento da Internet, ocorreu uma explosão de exposições desnecessárias dos corpos de alunos nas redes sociais. Nesses casos buscou-se analisar criticamente o desempenho da equipe pedagógica, mas também pôde ser observada a reação dos pais e responsáveis diante de cada fato que ocorreu na escola. Percebe-se, então, o receio, a vergonha e a inaptidão de muitos pais em falar sobre o assunto com os filhos, a punição era massivamente mais utilizada que o diálogo, mesmo no momento em que o(a) aluno(a) era o alvo da exposição.

Outro aspecto frequente que envolve situações constrangedoras é a utilização de músicas de cunho pornográfico pelos alunos, causando tumultos entre eles e deixando professores em situações embaraçosas. E é uma manifestação de um problema que não se deve desconsiderar, a pluralidade de músicas deste gênero é cada vez mais óbvia e imediata aos jovens. Diante dessas e muitas outras situações, a equipe pedagógica toma atitudes para resolvê-las que, em diversas ocasiões, por não serem do agrado dos pais, acabam por acarretar outros problemas ainda maiores. É uma questão de bom senso não tolerar expor crianças a conteúdos explícitos e pornográficos, mas é essencial refletir sobre eles. 
Assim, com base na problemática aqui exposta, esta pesquisa objetiva identificar qual a visão dos pais ou responsáveis pelos alunos sobre as possíveis intervenções realizadas pela escola em relação aos problemas pertinentes à sexualidade que ocorrem no seu cotidiano.

Tendo em vista o objetivo pretendido, a pesquisa embasou-se na aplicação de quatro situações-problema fundamentadas em fatos observados pelas autoras diretamente no dia a dia escolar. As situações-problema trazem à luz o impacto das demandas em torno da temática que emergem com frequência nas escolas, buscando identificar o ponto de vista, as considerações dos pais sobre uma provável intervenção pedagógica promovendo a argumentação acerca das possibilidades e formas de enfrentar e trabaIhar com as manifestações da sexualidade no dia a dia escolar e os problemas advindos dessa situação.

\section{REFERENCIAL TEÓRICO}

No Brasil, o tema sexualidade não é recente. Essa temática é discutida entre as políticas públicas e movimentos sociais desde o início do século 20. Desde então, a educação sexual tem passado por recuos e avanços, assim como seus objetivos têm-se modificado ao longo do tempo. No início, os interesses do Estado em torno da educação sexual era o controle da natalidade, o combate à masturbação, controlar o avanço das chamadas "doenças venéreas" e a preparação da mulher para desempenhar sua função social de esposa e mãe (BARROSO; BRUSCHINI, 1982).

De acordo com Figueiró (2009), os indivíduos, em sua maioria, ainda não compreenderam que as normas e valores em torno da sexualidade são sociais e historicamente construídos. Considerando que somos frutos de uma cultura repressora, pode-se observar uma ausência de liberdade e responsabilidade dos sujeitos em torno da própria sexualidade. Sabemos também que aquilo que é social e historicamente construído deve ser passível de análise e consequentemente de mudança.

Para Bruns e Melo (2016), com o atual cenário político e econômico que o país está vivendo, para além da crise econômica, se coloca a crise cultural e ideológica, em que a classe trabalhadora deve aceitar a visão de mundo da classe dominante. Segundo as autoras, a escola, a igreja e os meios de comunicação são os principais canais de transmissão do conhecimento, desta forma, esses meios tendem a ser recrutados para trabalhar a serviço das ideologias, a favor do capital. Assim, as autoras identificam a educação sexual como uma ação política para as liberdades individuais, e que está sendo muito questionada nos dias atuais.

Diante dessa contextualização da educação sexual no Brasil, identifica-se as influências externas nesse processo de avanços e retrocessos descritos pelos autores referenciados, e é a partir dessa construção que podemos identificar nos dias atuais a relação que se estabelece entre a família e a escola quanto a essa questão.

As instituições escola e família, de acordo com Dessen e Polonia (2007), constituem contextos de desenvolvimento fundamentais para os indivíduos, desempenhando a função de motivar ou reprimir o progresso físico, intelectual, psicológico e social. Nesse contexto, não podemos estabelecer uma definição universal de família, quando 
sabemos que elas são diversas e multifacetadas, contudo, de forma geral, as funções sociais da família se constituem como "um sistema de transmissão de valores e cultura" (DESSEN; POLONIA, 2007, p. 22).

Louro (2014) traz uma perspectiva contemporânea sobre o impacto da escola nas relações sociais. Para esta autora, a escola que inicialmente possuía função de acolher, ao longo do tempo, influenciada pela sociedade moderna, passou a separar os indivíduos, os adultos das crianças, os católicos dos protestantes, os meninos das meninas e os pobres dos ricos. E nessa relação dialética a sociedade influencia a escola e a escola influencia as relações sociais, inclusive a família.

A família, sendo modelo para aqueles que estão sob a sua responsabilidade, é reforçada pelas leis do nosso país, que não é exceção entre as inúmeras culturas existentes no mundo. Desta forma, o processo de socialização dos indivíduos se dá primeiramente e em maior parte na família que, embora consciente ou não da relevância de suas funções, transmite "hábitos, valores, crenças e conhecimentos que acredita serem úteis para a inserção dos filhos na sociedade" (SZYMANSKI, 2004, p. 2).

Para Oliveira e Vianna (2017), a escola se diferencia da família à medida que na primeira se estabelecem relações mais diversas, o que por vezes não ocorre na família, que tende a ser mais homogênea; assim, as relações estabelecidas no contexto escolar levam o indivíduo a questionar as relações estabelecidas no seio familiar. Os autores afirmam ainda que as vivências familiares propiciam a construção de repertórios comportamentais, que influenciarão inclusive na percepção do indivíduo em relação à escola e ao processo educacional, bem como nas possíveis transformações sociais. É importante destacar, contudo, que a recíproca é verdadeira, pois o desenvolvimento tecnológico e as transformações sociais, em geral, também tendem a modificar as estruturas e as dinâmicas familiares ao longo da História (DESSEN; POLONIA, 2007, p. 22).

A instituição escolar passou por diversas fases e transformações ao longo da História. Em sua configuração atual possui, como função social, o desenvolvimento das potencialidades dos indivíduos, como conhecimentos, habilidades, atitudes e valores que objetivam desenvolver sujeitos capazes de se tornarem cidadãos conscientes da vida coletiva e participativos na sociedade em que vivem (POSSAMAI, 2014).

Dessen e Polonia (2007) corroboram a fala de Possamai (2014), quando afirmam que a escola funciona como um microssistema de vivências, que prepara o indivíduo para a vida em sociedade.

Werebe (1977) aponta a dificuldade dos educadores em trabalhar o tema, trazendo a repressão como um elemento de controle, diante das suas intervenções, por vezes omissas, ou atribuindo gravidade àquilo que é natural em cada fase de desenvolvimento. Assim como a família, a escola também desempenha um papel importante na construção da personalidade dos indivíduos, os educadores transmitem mensagens a todo momento, conforme seus comportamentos, formas de se vestir e de interagir com os alunos. Os conteúdos também são carregados de mensagens veladas, ideias, valores sobre gênero, sexualidade e papéis sociais. 
A escola é o local de maior socialização de crianças e adolescentes após a instituição familiar, portanto muito se aprende para além dos livros e das atividades realizadas em sala de aula. A sexualidade como parte dos aprendizados cotidianos deverá ser inserida com naturalidade, mas tal inserção também dependerá da concepção e apoio da família, que possui um papel crucial no processo educativo (FIGUEIRÓ, 2009). Complementando a visão de Figueiró, Fernández, Fernández e Castro (2007) ressaltam que a família é um dos agentes mais importantes de aprendizado para um indivíduo, contudo os filhos possuem outras vivências para além da família como as experiências vividas na escola que irão agregar nesta construção.

\section{PROCEDIMENTOS METODOLÓGICOS}

Este estudo caracteriza-se como pesquisa de cunho qualitativo e descritiva que, segundo Vergara (2000, p. 47), objetiva expor as características de determinada população ou fenômeno. Para a caracterização da pesquisa concluiu-se que o método qualitativo é o ideal para identificar a subjetividade que compõe a concepção dos indivíduos, pois segundo Minayo (2010), é o método que se aplica ao estudo da história, das relações, das crenças, das percepções e das opiniões, produtos das interpretações que os humanos fazem a respeito de como vivem, constroem artefatos e a si mesmos, sentem e pensam.

Para obtenção dos dados foram elaboradas quatro situações-problema para suscitar a reflexão dos responsáveis sobre o tema proposto, apresentadas mediante assinatura do Termo de Consentimento Livre e Esclarecido. O instrumento de coleta de dados passou por um processo de avaliação ética em pares, de profissionais da área de pesquisa em educação sexual, bem como profissionais da área da Psicologia que puderam avaliar se as perguntas poderiam gerar algum dano ou constrangimento aos participantes do estudo.

Optou-se por utilizar também situações-problema que partem da realidade vivida na escola. Desse modo, as quatro situações-problema apresentadas neste estudo ocorreram na escola onde a coleta de dados foi realizada. As situações-problema permitem maior proximidade com o conteúdo empírico, "suscitando que questões norteadoras iniciais sejam levantadas com vistas a tornar tal realidade mais explícita para o pesquisador" (RAUPP; BEUREN, 2006, p. 94).

O local escolhido para a realização da pesquisa foi um colégio estadual da zona sul da cidade de Londrina/PR. Nessa escola ocorre trimestralmente uma reunião pedagógica em que todos os responsáveis pelos alunos são convocados a participar. Após a reunião foi esclarecido sobre a pesquisa e todos os pais e responsáveis foram convidados a fazer parte. $\mathrm{O}$ número de participantes não foi definido a priori, considerando que o caráter era voluntário. Diante de um universo de 140 responsáveis, compareceram na reunião 40 e, destes, 22 se dispuseram a participar da pesquisa.

Os participantes deste estudo são os responsáveis pelos alunos dos quatro sextos anos do Ensino Fundamental e todos os que se dispuseram a participar eram pais ou mães, não havendo outro grau de parentesco. O motivo pelo qual escolhemos essa fase de escolaridade é, além de ser a idade do início da puberdade em que ocorrem mudanças físicas significativas e a curiosidade é bastante aguçada, também é o momento em que os 
adolescentes então ingressando nos anos finais do Ensino Fundamental e a escola nessa fase apresenta-se com diferenças relevantes em relação àquelas dos anos iniciais das quais vieram os estudantes. Dessa forma, faz-se impreterível a escolha dos pais ou responsáveis pelos alunos e alunas ingressantes, ou seja, dos sextos anos, para apresentarem suas visões quanto às situações que envolvam a sexualidade no ambiente escolar e, além disso, refletirmos a partir dos dados obtidos, sobre ações e desdobramentos das possíveis intervenções de forma progressiva e eficiente ao longo dos demais anos escolares.

A pesquisa foi submetida ao Conselho de Ética em Pesquisa - CEP - e foi aprovada, indicado pelo parecer $n=2.592 .998$. Todos os participantes assinaram o Termo de Consentimento Livre Esclarecido.

\section{APRESENTAÇÃO E DISCUSSÃO DOS DADOS}

As respostas das situações-problema foram analisadas e categorizadas, conforme Gomes (2009). Para o autor, podemos encontrar diversas formas de analisar a mensagem do participante, por meio da decomposição e tratamento do conteúdo obtido. Após a coleta dos dados foi realizada uma leitura geral das respostas e procurou-se observar quais termos e ideias se repetiam. As colocações semelhantes foram divididas em categorias, até que se esgotassem e restassem apenas aquelas que não se encaixavam ou que não eram coerentes às perguntas, definidas, por exemplo, como "outras colocações". Após a divisão das categorias foi feita uma breve descrição e posteriormente uma análise baseada nos autores utilizados na pesquisa. Para a preservação da identidade dos participantes, optou-se por utilizar a inicial $(R)$ de responsável, e as letras do alfabeto, dessa forma, os participantes são RA, RB, RC e assim sucessivamente. Em cada uma das situações-problema apresentadas os pais teriam de responder como a escola deveria proceder.

A situação-problema 1 apresenta um caso de Sexting. A direção e alguns professores da escola tomam conhecimento de que uma foto de conteúdo de nudez, de um dos alunos, está circulando nas redes sociais entre os demais adolescentes da escola. A partir das respostas foram elencadas cinco categorias. $O$ quadro 1 apresenta resultados da situação-problema 1.

Quadro 1 - Caso de Sexting

\begin{tabular}{|c|c|c|}
\hline CATEGORIAS & BREVE DESCRIÇÃO & RESPONSÁVEIS \\
\hline $\begin{array}{l}\text { Escola e } \\
\text { responsáveis }\end{array}$ & $\begin{array}{l}\text { A escola deve chamar os responsáveis } \\
\text { dos envolvidos e resolverem juntos. }\end{array}$ & $\begin{array}{l}R A, R F, R G, R J, R L, R O, R I \text {, } \\
R P, R X, R V, R R, R T, R N\end{array}$ \\
\hline Escola e envolvidos & $\begin{array}{l}\text { A escola deve resolver somente com os } \\
\text { envolvidos. }\end{array}$ & $\mathrm{RB}, \mathrm{RC}, \mathrm{RS}, \mathrm{RM}, \mathrm{RH}$ \\
\hline $\begin{array}{l}\text { Escola, responsáveis e } \\
\text { outros órgãos }\end{array}$ & $\begin{array}{l}\text { Escola, responsáveis e órgãos } \\
\text { competentes (Conselho Tutelar, entre } \\
\text { outros) devem resolver juntos a } \\
\text { questão. }\end{array}$ & $\mathrm{RQ}, \mathrm{RU}$ \\
\hline $\begin{array}{l}\text { Escola, responsáveis e } \\
\text { alunos }\end{array}$ & $\begin{array}{l}\text { A escola deve orientar os alunos e os } \\
\text { responsáveis }\end{array}$ & RE \\
\hline Não opinante & Não emite opinião sobre o fato ocorrido & RD \\
\hline
\end{tabular}


Este movimento de enviar fotos de nudez, relatado na situação-problema 1, tem ocorrido no mundo todo e não apenas entre os adolescentes, mas em todas as faixas etárias. O nome dado para tal prática é sexting, que se traduz como "troca de mensagens com cunho erótico". De acordo com Barros e Ribeiro (2017), o termo engloba qualquer conteúdo sexual próprio disseminado na Internet, sendo a pessoa que o envia ou enviada por terceiros. Segundo 14 pais dos 24 participantes, diante de um caso de sexting a escola deve comunicá-los e resolverem juntos a situação. Observa-se também que ao invés de sugerirem espaços de discussões e reflexões sobre a importância de tratar o assunto não como escândalo, mas como fato que pode acontecer pela curiosidade devido à idade, os responsáveis defendem que o assunto deve ser tratado de maneira velada, só com os envolvidos, como se os seus filhos não fizessem parte deste cenário. Nesse sentido, é importante considerar que a obtenção do celular foi proporcionada pelos pais, porém seu acesso não é controlado por eles. Na sequência elencamos as respostas dos participantes:

RA: "Acho que a escola deve de imediato procurar uma maneira de proibir o conteúdo na escola e conversar com os pais o mais rápido possível para que estes conversem e tomem providências com seu filho ou filha".

RN: "Nesse caso deveriam ser chamados os pais dos envolvidos e, com uma boa conversa, tentarem solucionar o mais rápido possivel e tirar esse conteúdo das redes sociais".

RR: "Explicar que nosso corpo deve ser preservado e ninguém pode ver, apenas nós mesmos. Descobrir o responsável pela foto e juntamente com os pais decidir qual decisão tomar sobre o ocorrido".

RT: "A direção deve comunicar aos pais da vítima e também dos autores da edição e propagação deste conteúdo".

RF: "Dirigir-se até o aluno para ajudá-lo, às vezes foi feito na maldade, e o adolescente precisará de ajuda para enfrentar isso, e óbvio que chamar os pais para que eles tenham conhecimento sobre o que se passa".

RI: "Acho que deveria ser proibido o uso de celulares na hora do intervalo, ou dentro da escola, e orientação começando em casa para que não aconteça grupo de crianças na escola, que seja apenas para uso de trabalhos e escola, e chamarem os responsáveis para conhecimento do assunto".

RJ: "Proteger a exposição desse aluno, comunicar aos pais e descobrir o divulgador e tomar providências".

RL: "Tem que chamar o aluno que está sendo exposto e o porquê e quem postou e os pais fiscalizarem os telefones dos filhos".

RP: "Ela deveria conversar com os pais da adolescente e porque às vezes eles mesmos se oprimem e não contam".

RG: "Abordar diretamente com todos os alunos e com os pais sobre o fato, expondo as consequências e trabalhando junto para contorná-lo de maneira a não deixar sequelas aos envolvidos e à escola".

RO: "Tem que chamar os pais e sentarem para ver o que aconteceu e tomar medidas cabiveis". 
RX: "Procurar abordar os responsáveis e tentar acabar com o problema, lembrando que esse tipo de coisa começa em casa, então os pais têm que estar alertas".

Por outro lado, para cinco dos pais participantes, a escola deve resolver apenas com os envolvidos, o que mostra uma falta de compreensão ou ainda que podem não estar informados sobre as possíveis consequências e impacto na vida do indivíduo que vivencia tamanha exposição. Não se visualiza nas respostas dadas que a educação sexual é de responsabilidade da família e que toda a comunidade escolar, incluindo os pais, deve compartilhar informações seguras aos jovens, mas não somente em momentos pontuais como este. Considera-se que os pais devem assumir suas responsabilidades e compreenderem que não cabe à escola suprir a ausência da família, mas a de criar espaços para compartilhar informações seguras e permitir que os jovens tragam suas dúvidas e questionamentos. Para Barros e Ribeiro (2017), após a disseminação de um conteúdo íntimo, alguns jovens cometem suicídio e muitos desenvolvem um transtorno de ansiedade e depressão em decorrência do trauma gerado. As respostas dos pais que demonstram não ser de sua responsabilidade estão expostas a seguir:

RB: "Os envolvidos devem ser ouvidos e verificado como aconteceu e verificar o que pode ser feito para correção da conduta (como a foto foi enviada) sem permissão? Com permissão (do aluno nu)".

RC: "Tinham que ver primeiro a pessoa que colocou isso nas redes sociais e depois resolver a situação".

RH: "Acredito que a escola deva resolver isso junto às partes envolvidas".

RM: "Acredito que a direção deva chamar os envolvidos para uma conversa e esclarecimentos sobre o conteúdo, deixando claro que a escola não aceitará este tipo de atitude no ambiente escolar".

RS: "A escola deve orientar que isso é uma coisa que talvez não prejudique o(a) aluno(a), mas isso não deve acontecer nunca mais".

A punição em torno dos casos de sexting já é algo do campo judicial. Barros e Ribeiro (2017) afirmam que, apesar de já existir lei que objetiva coibir tal prática, as autoras reforçam a necessidade de um trabalho preventivo da escola em conjunto com a família. As respostas a seguir remetem aos participantes que consideram ser necessário encaminhar as situações para setores competentes, como o Conselho Tutelar ou a Justiça. É possível observar que não apontam soluções que envolvam a todos quanto a tratar os temas relativos à sexualidade em espaços seguros, atribuindo sempre aos outros a responsabilidade pelas possíveis soluções.

RQ: "Olha, minha opinião é a chamada dos pais e do Conselho Tutelar porque hoje em dia se previne muito".

RU: "Chamar os responsáveis, pais e mães, e conversar para tirar da rede e, se não adiantar, autoridades competentes". 
Apenas um dos responsáveis aponta claramente para a importância em falar com os pais e orientar os alunos, diante da situação relatada. Um dos pais não propõe uma intervenção, apenas afirma que o fato não pode ocorrer, contudo, de acordo com Barros e Ribeiro (2017), esses casos podem não acontecer se houver diálogo e informações sobre os riscos.

Considera-se, diante das respostas dos pais, que 16 deles destacam a função dos pais na resolução. Quando os pais afirmam que pode ser necessário encaminhar as situações para outros setores responsáveis, como o Conselho Tutelar, isso revela conhecimento de que é direito da criança ser protegida desse tipo de exposição, considerada crime, de acordo com o artigo 241 do Estatuto da Criança e do Adolescente (1990). Quando, no entanto, respondem que a escola deve se responsabilizar sozinha e resolver com os envolvidos, sem a participação de pais e mães na situação, mostra um movimento contemporâneo de responsabilização da escola e isenção dos responsáveis na educação integral. De acordo com Carvalho (2004), a relação entre escola e família deve ser de divisão das responsabilidades. Ao se tratar de conhecimentos, a delimitação da função de cada uma dessas instituições não é clara e, segundo o autor, é permeada por um ideal tanto da família quanto da escola sobre o papel de cada uma.

Na sequência são apresentados os resultados da situação-problema 2, que se refere à masturbação. A situação foi colocada aos pais da seguinte forma: "Um aluno é pego se masturbando na sala de aula, a professora o encaminha para a equipe pedagógica". A partir das respostas foram elencadas seis categorias. Os dados relativos a esta situação-problema estão apresentados no Quadro 2.

Quadro 2 - Caso de masturbação em sala de aula

\begin{tabular}{|l|l|l|}
\hline \multicolumn{1}{|c|}{ CATEGORIAS } & BREVE DESCRIÇÃO & RESPONSÁVEIS \\
\hline $\begin{array}{l}\text { Escola } \\
\text { orienta o aluno }\end{array}$ & $\begin{array}{l}\text { A escola conversa apenas com o aluno e o } \\
\text { orienta sobre sua conduta. }\end{array}$ & RP, RR, RS \\
\hline $\begin{array}{l}\text { Escola } \\
\text { pune o aluno }\end{array}$ & $\begin{array}{l}\text { A escola conversa apenas com o aluno e lhe } \\
\text { aplica uma punição. }\end{array}$ & RF, RJ, RV, RX \\
\hline $\begin{array}{l}\text { Escola e responsáveis } \\
\text { orientam o aluno }\end{array}$ & $\begin{array}{l}\text { A escola, juntamente com os responsáveis, deve } \\
\text { resolver a questão com o aluno. }\end{array}$ & $\begin{array}{l}\text { RA, RC, RE, RG, } \\
\text { RI, RM, RO, RT }\end{array}$ \\
\hline $\begin{array}{l}\text { Acompanhamento } \\
\text { psicoterapêutico }\end{array}$ & $\begin{array}{l}\text { O aluno deve ser encaminhado pela escola } \\
\text { para um acompanhamento psicoterapêutico. }\end{array}$ & RB, RN, RU \\
\hline $\begin{array}{l}\text { Os responsáveis } \\
\text { devem resolver }\end{array}$ & $\begin{array}{l}\text { Os responsáveis do aluno devem resolver com o o } \\
\text { aluno esta questão. }\end{array}$ & RH, RL \\
\hline Outras opiniões & $\begin{array}{l}\text { Não descrevem como a escola deve proceder } \\
\text { neste caso. }\end{array}$ & RD, RQ \\
\hline
\end{tabular}

Fonte: Dados da pesquisa.

Furlani (2011) argumenta que a descoberta corporal é a expressão natural da sexualidade e todos os indivíduos passarão por tal fase, contudo a autora destaca a importância em trabalhar com a criança sobre a noção de intimidade e privacidade pessoal, em que o indivíduo saiba identificar o local seguro e adequado para conhecer o próprio corpo. Três participantes consideram que a escola deve orientar o aluno, não mencionando a função dois pais nestes casos. 
RP: "Esta equipe terá que estar preparada para orientar este adolescente de suas emoções porque até para eles pode ser estranho".

RR: "O aluno deve ser orientado que esse tipo de situação é privacidade dele. Não deve ser feito em público".

RS: "Conversar que na escola não é lugar pra esse tipo de coisa e se for muito novo esperar o momento certo para acontecer a vida sexual".

Outros quatro participantes admitem que a punição seja a melhor alternativa de intervenção, demonstrando despreparo quanto ao fato, conforme respostas a seguir:

RF: "Nesse caso acredito que terá que conversar com ele, fazê-lo entender que é errado, pois há várias pessoas no mesmo local, e aplicar uma advertência".

RX: "Acionar os responsáveis desse aluno e seria cabível algum tipo de punição para que não se repita mais o ato".

RJ: "Tá certo, tem que punir conforme os seus atos porque na escola ele veio para aprender a educação escolar".

RV: "Imediatamente, e este aluno deve ser punido pelo ato que fez, pois a escola é lugar de estudar, e ele vai aprender a lição e claro após reunião com os pais e eu acredito que os pais têm que ser advertidos".

No entendimento de Maksud (2008), a prática da masturbação é historicamente punida como uma atividade sexual pecaminosa. Atualmente sabe-se que não causa nenhuma doença e que se trata de uma prática saudável, exceto em casos de compulsão, contudo para a autora a prática ainda é reprimida, mesmo quando realizada em momentos e locais adequados. Oito responsáveis admitem que a situação deve ser resolvida pela escola com o auxílio dos pais, ou vice-versa.

RA: "Acho que o pedagogo deve conversar num primeiro momento com o aluno e após com os pais do aluno, se necessário com ambos juntos para que possam ver uma maneira de resolver a situação".

RC: "Chamar a atenção dele, chamar os pais para uma grande conversa".

RE: "Entender o porquê desta atitude, chamar os pais para passar a situação e ambos possam ajudar em outros comprometimentos".

RG: "Chamar os pais, expor a situação ocorrida e juntos conscientizar o aluno da situação e escutar dele sua opinião e mostrar a ele que seu comportamento não estava correto para aquele ambiente e conscientizá-lo, junto com os pais, do tema".

RI: "Acho que na idade os pais e responsável devem conversar junto com a equipe pedagógica para conhecimento, pois às vezes os pais não estão sabendo orientar".

RM: "A posição da equipe pedagógica é chamar os pais para uma conversa para explicar a situação e ver o que de fato está levando este adolescente a fazer e ter este comportamento em sala de aula, pois no ambiente escolar não é o lugar nem a hora para este tipo de atitude".

RO: "Acho que os pais têm que saber o assunto e ver o porquê do ato".

RT: "Sim e também comunicar e intimar os pais responsáveis por este aluno". 
Três pais afirmam que a criança que é pega se masturbando na escola deve ser encaminhada para o acompanhamento psicoterapêutico. Para Maksud (2008), a masturbação tende a ser vista como distúrbio ou doença ainda nos dias de hoje, considerando a falta de habilidade dos indivíduos em lidar com tal situação, que é do âmbito da individualidade.

RB: "Acredito que o aluno necessite de tratamento terapêutico".

RN: "Acho que esse aluno precisa de uma ajuda profissional, como um psicólogo, precisa de uma boa orientação".

RU: "Sim, que ele não seja ridicularizado automaticamente. Pai e mãe e um trabaIho de orientação com psicólogo".

Conforme Furlani (2011), ao olhar do adulto, a prática da masturbação leva à noção de perversão que, por vezes, espanta os pais, que tendem a considerar a prática anormal e buscar na Psicologia uma tentativa de normatização dos filhos. Dois responsáveis consideram que resolver tal situação é função da família, a escola deve apenas informá-los.

Outros dois pais não pontuam possíveis intervenções na situação relatada. Conclui-se, portanto, que a tendência é de os adultos considerarem a masturbação um desvio de comportamento, no entanto, de acordo com Maia e Aranha (2005), a escola e a família devem compreender e trabalhar cada momento vivenciado pela criança ou adolescente, a descoberta corporal faz parte do desenvolvimento e pode ser tema de diálogo e não de repressão, para que os alunos entendam que não é errado praticar a masturbação, apenas que isso deve ser realizado em momento e local adequados.

A seguir apresentamos a situação-problema 3, referente a um caso de gravidez na adolescência: "Uma aluna de 14 anos engravida e gera grande comentário entre os demais alunos". Foram elencadas sete categorias. Os dados estão organizados no Quadro 3.

Quadro 3 - Gravidez na adolescência

\begin{tabular}{|l|l|l|}
\hline CATEGORIAS & BREVE DESCRIÇÃO & RESPONSÁVEIS \\
\hline $\begin{array}{l}\text { Escola orienta os } \\
\text { alunos }\end{array}$ & A escola deve fazer orientação aos alunos. & $R E, R F, R N, R V$ \\
\hline $\begin{array}{l}\text { Escola orienta a } \\
\text { aluna e os seus } \\
\text { responsáveis }\end{array}$ & A escola orienta a aluna e seus responsáveis. & $R A$ \\
\hline $\begin{array}{l}\text { Escola orienta a } \\
\text { todos }\end{array}$ & $\begin{array}{l}\text { A escola orienta a aluna, seus responsáveis e } \\
\text { demais alunos. }\end{array}$ & $R G, R H, R X$ \\
\hline $\begin{array}{l}\text { Escola orienta e } \\
\text { pune os envolvidos }\end{array}$ & A escola pune os envolvidos no fato ocorrido. & $R T$ \\
\hline $\begin{array}{l}\text { A escola orienta } \\
\text { somente a aluna }\end{array}$ & $\begin{array}{l}\text { A escola deve realizar orientações apenas à } \\
\text { aluna gestante. }\end{array}$ & $R C, R M, R P, R S$ \\
\hline $\begin{array}{l}\text { Escola e/ou } \\
\text { responsáveis } \\
\text { orientam }\end{array}$ & $\begin{array}{l}\text { A escola e a família fazem um trabalho de } \\
\text { orientação juntamente com os responsáveis. }\end{array}$ & $R B, R Q, R I, R U$ \\
\hline Outras opiniões & Outras opiniões sobre o assunto. & $R D, R O, R R, R L, R J$ \\
\hline
\end{tabular}

Fonte: Dados da pesquisa. 
Quatro dos 22 pais participantes consideram que a escola deve fazer orientações para todos os alunos, para a aluna gestante e para a família. De acordo com Bruns e Melo (2016), a escola não deve se omitir diante das situações que ocorrem com os educandos, levando informações e conversando diante das demandas cotidianas. Observa-se um higienismo e fundamentalismos religiosos quando apontam "cuidados", "doenças", "só depois do casamento".

RE: "Fazer uma palestra sobre os cuidados do sexo na adolescência e gravidez $e$ doenças e mostrar formas de como proteger a si mesma".

RF: "Fazer uma reunião com a sala e explicar que não é correto fazer isso, pois cada caso é um caso e fazendo comentários pode prejudicar a amiga e gerar até problemas. Acredito que com uma boa conversa tudo se resolve".

RN: "Acho que é o caso de abordar esse assunto em sala de aula, ela dar o relato para que os demais tomem os devidos cuidados para que não ocorra com eles também".

RV: "Tratar com naturalidade, pois isso acontece com frequência em muitas famílias, e caso seja necessário para acalmar os alunos, relatar a todos o que aconteceu com naturalidade, mas também ressaltar que com 14 anos é cedo demais para ser mãe, que ser mãe é somente após o casamento, simples assim".

Apenas um dos responsáveis acredita que a intervenção da escola deve ser apenas com a aluna e sua família, o que mostra preocupação da maioria dos pais em trabaIhar a prevenção da gravidez no contexto escolar.

RA: "Deve-se conversar com a aluna e após com os pais do aluno, se possivel até mesmo a escola fazer um encaminhamento do mesmo para uma consulta ao psicólogo com acompanhamento, já que o aluno terá toda uma mudança de vida; já relacionado aos demais é importante que a escola aconselhe que a aluna mesma dê a notícia para os alunos para evitar comentários desagradáveis".

Apenas três pais compreendem que todos precisam ser orientados pela escola, a aluna, os demais alunos e os seus responsáveis.

Para outro responsável, a solução é punir aquele que estiver comentando, no entanto o comentário pode significar a curiosidade ou falta de compreensão sobre o tema, que para Figueiró (2009) é o indicativo de que aquele tema deve ser trabalhado naquele momento.

Os participantes RC, RM, RP e RS demonstraram preocupação apenas com a orientação da aluna gestante.

RC: "Essa aluna tinha que passar por um psicólogo e também dar muito apoio para ela".

RM: "A escola deve chamar esta adolescente para fazer parte de um projeto, para que isso não ocorra com outras jovens, porém não apontando o dedo, mas fazendo com que esta adolescente se sinta importante e mostre suas experiências a seus colegas".

RP: "Comentários sempre existem. Terão que trabalhar o psicológico da adolescente para que o pior não aconteça". 
RS: "Deve orientar que isso não é coisa fora do normal, com 14 anos dependendo do tipo de menina já tem responsabilidade pra cuidar do seu filho".

Quatro pais apontam a importância da família e também da escola, na busca da prevenção da gravidez na adolescência.

RB: "A escola e pais devem trabalhar o assunto de gravidez precoce, para que próximos casos não ocorram".

RQ: "Porque esta não teve uma conversa com a família por isso que gera um comentário deste".

RU: "Cabe a nós orientarmos os demais, não que é normal, mas vai acarretar algumas responsabilidades que o adolescente não está preparado".

RI: "Falta de conhecimento e orientação, apesar de ter colocado (não) pela idade da minha filha, que ainda não tem interesse pelo assunto, mas nessa idade a orientação já deve ser passada para não acontecer, porém depois de já engravidar tem que cuidar para que não aconteça novamente".

Os participantes RO, RJ, RD, RL e RR foram alocados na categoria "outras opiniões" por não determinarem uma intervenção por parte da escola neste caso, ou em alguns casos não delimitarem a quem a intervenção deve ser direcionada e indicarem "agora não tem mais jeito", "não deveria estudar", "o que os outros vão pensar" "afastar", "não pode acontecer", ressaltando um falso moralismo, como se esta situação estivesse longe deles e não fizesse parte do seu entorno.

RO: "Por isso a educação sexual é importante tanto na escola como em casa com os pais".

RJ: "Bom, agora não tem jeito, o melhor é usar o caso como exemplo de que um filho não planejado vai lhe trazer boa parte de sua vida interrompida".

RL: "Acho que não deveria estudar, nessa idade grávida e os outros alunos o que vão pensar já que ela pode eu posso, acho que devia afastar ela, passar por psicóloga e os pais também".

RD: "Não pode acontecer".

RR: "Os demais alunos devem ter em mente que a gravidez na adolescência pode ocorrer e que causará "problemas" como a perda da liberdade. Que tudo tem a hora certa".

Compreende-se, diante de todas as respostas e do número expressivo de pais que não propõem uma intervenção por parte da escola, que ainda há dúvidas de como lidar diante de uma situação como esta. Um dos pais sugere, inclusive, que a aluna não deva mais estudar, o que é determinar uma punição a ela e não se importar com as consequências que isso pode gerar, em termos de curiosidades e julgamentos por parte dos demais alunos. Para Figueiró (2007), casos como estes requerem uma intervenção imediata por parte de todos. Os alunos, a aluna e a família devem encontrar espaço para o diálogo, isento de julgamentos, que não ajudarão neste momento. A autora sugere ainda que se deve conversar sobre tudo que envolve a gravidez, como sentimentos e 
comportamentos, não enfocando apenas a situação em si. O que se pode concluir é que nem a escola e nem os pais devem se omitir diante do fato, acolher e dialogar é a melhor opção.

Apresentamos na sequência a última situação-problema referente à utilização de músicas de conteúdo pornográfico, isto é, que utilizam palavrões ou ainda relacionam a sexualidade a aspectos obscenos e o corpo como objeto de desejo sexual. "A professora, ao entrar na sala, percebe que os alunos estão ouvindo uma música com letra de conteúdo pornográfico". A partir das respostas foram estabelecidas seis categorias. As respostas estão no Quadro 4.

Quadro 4 - Música de conteúdo pornográfico

\begin{tabular}{|l|l|l|}
\hline CATEGORIAS & BREVE DESCRIÇÃO & RESPONSÁVEIS \\
\hline $\begin{array}{l}\text { A escola deve punir os } \\
\text { envolvidos }\end{array}$ & $\begin{array}{l}\text { A escola deve adotar medidas para } \\
\text { punir os alunos que tiverem esse tipo de } \\
\text { comportamento. }\end{array}$ & $R V$ \\
\hline $\begin{array}{l}\text { A escola deve orientar os } \\
\text { envolvidos }\end{array}$ & $\begin{array}{l}\text { A escola deve orientar os alunos sobre } \\
\text { este comportamento. }\end{array}$ & $\begin{array}{l}\mathrm{RB}, \mathrm{RM}, \mathrm{RN}, \mathrm{RP}, \mathrm{RR}, \\
\mathrm{RS}, \mathrm{RU}, \mathrm{RF}, \mathrm{RH}\end{array}$ \\
\hline $\begin{array}{l}\text { A escola deve orientar os } \\
\text { envolvidos e família }\end{array}$ & $\begin{array}{l}\text { A escola deve orientar os envolvidos e } \\
\text { família. }\end{array}$ & $\mathrm{RE}, \mathrm{RL}$ \\
\hline A escola deve proibir & A escola deve punir este tipo de música. & $\mathrm{RA}, \mathrm{RI}, \mathrm{RJ}, \mathrm{RO}$ \\
\hline $\begin{array}{l}\text { A escola deve orientar a } \\
\text { todos }\end{array}$ & $\begin{array}{l}\text { A escola deve orientar os envolvidos, os } \\
\text { demais alunos e os responsáveis. }\end{array}$ & $\mathrm{RG}$ \\
\hline Outras opiniões & $\begin{array}{l}\text { Emitiram opiniões que não se enquadram } \\
\text { nas demais categorias }\end{array}$ & $\mathrm{RC}, \mathrm{RT}, \mathrm{RD}, \mathrm{RQ}, \mathrm{RX}$ \\
\hline
\end{tabular}

Fonte: Dados da pesquisa.

Um participante acredita que os alunos devam ser punidos por ouvir músicas pornográficas na escola. Outros nove afirmam que a escola deve orientar os alunos para que estes comportamentos não se repitam:

RB: "Muito difícil, pois hoje muitas músicas são pornográficas. Porém devem ser advertidos".

RF: "Pedir para o aluno desligar, pois dentro da escola tem que ter respeito, pois nem todos gostam desse tipo de música".

RH: "Penso que a escola deve ter normas sobre esses assuntos, e se acaso um aluno não respeite, então a escola tome as atividades cabíveis".

RM: "Acredito que ela deve pedir para que desliguem a música, pois aqui é um ambiente escolar e este tipo de música sem conteúdo não tem nada a acrescentar".

RN: "Exigir que desliguem e explicar que não é legal, principalmente em sala de aula".

RP: "Orientá-los que este tipo de letra não Ihes trará nada de positivo".

RR: "Ela deveria falar que esses tipos de música desrespeitam a moral e que existem músicas adequadas à idade deles".

RS: "Deve orientar os alunos a ouvirem outro tipo de música, pois essas músicas que estão ouvindo não irão fazer bem para a mente deles". 
RU: "Primeiro lugar, muito claro, sala de aula não é o ambiente. Retirar o aluno e orientar"

Dois responsáveis destacam a importância em orientar os alunos e contar com os pais neste processo. Quatro deles afirmam que a intervenção ideal é a proibição diante de casos como estes.

RA: "Acho que a escola deve ter uma regra de proibição para esse tipo de música, porém apenas dentro da escola, fora isso é questão de os pais observarem, já que cada família tem uma maneira de viver".

RI: "Na minha casa não deixo as crianças ouvirem músicas pornográficas e nem televisão, deveria ser proibido na escola também".

RO: "Na escola não é o local adequado para esse tipo de música, não tem que deixar".

RJ: "Tomar o celular do aluno e mostrar que a única intenção dele estar na sala de aula é que ele está ali para aprender a ser um cidadão".

Apenas um dos pais destaca a importância da escola em orientar os envolvidos, os demais alunos e também os responsáveis. Outros responsáveis também expressam suas preocupações diante do comportamento dos filhos em ouvir músicas de conteúdo pornográfico no ambiente escolar, contudo não sugerem intervenções que possam ser realizadas pela equipe escolar.

RC: "Eu penso que falar sobre relação sexual é uma coisa que tem a hora e o tempo do professor".

RT: "Não pode permitir a entrada de aparelhos nas salas de aula, é minha opinião".

RD: "O correto é não escutar nem uma música, pior uma com conteúdo pornográfico".

RQ: "Meu Deus, isso é reprovável, mas hoje em dia é muita música suja feia, você vai falar alguma coisa e fica pior".

RX: "Parar a ação e se eles ouvem em casa o pai e a mãe gostam, certamente vai querer mostrar aos amigos".

Diante de todas as intervenções propostas pelos pais, como orientação e punição, podemos analisar, segundo Fernandes, Reina e Wokwa (2015), que a música é a expressão da cultura e do momento vivido em sociedade e que reprimir não é o melhor caminho. Para os autores, a intervenção mais adequada da escola deve ser refletir sobre a situação com os alunos, levá-los a pensar e, em contrapartida, oferecer alternativas musicais que ressaltem a cultura e que também despertem o interesse deles, ao mesmo tempo que desenvolvem o senso de cultura e responsabilidade com o próprio comportamento.

Para Cabral e Souza (2017), muitas discussões a respeito da sexualidade têm ocorrido em todas as sociedades, porém a dificuldade em falar sobre o assunto, mesmo na contemporaneidade, continua dominando principalmente os espaços das escolas. Muitos educadores, pais e professores, têm uma visão da sexualidade como algo que fere 
a moral e está relacionado ao pecado, como observa Furlani (2011). Para a autora, o espaço escolar deve ser visto como o local que favorece o desenvolvimento integral do indivíduo, fortalecendo os direitos e o exercício da cidadania.

\section{CONSIDERAÇÕES FINAIS}

A análise das situações-problema apresentada para 22 responsáveis que se dispuseram a participar da pesquisa demonstrou que os pais esperam da escola intervenções assertivas diante de situações pertinentes à sexualidade, contudo apresentam divergências sobre o que consideram uma intervenção ideal por parte da escola. Muitas respostas demonstram receio sobre a forma como serão abordadas as questões, considerando que poderão despertar a sexualidade precocemente nos estudantes, revelando falta de informação sobre o real objetivo da educação sexual na escola. A pesquisa despertou, então, a necessidade de realizar uma intervenção com a intenção de desmistificar a proposta da educação sexual e aponta para a relevância de intervenções na escola diante das demandas da educação sexual, não somente com os discentes, mas também com os pais e responsáveis. Seria ideal que o contexto educacional promovesse espaços que possibilitassem abordar, escutar, discutir e refletir sobre temas relacionados à sexualidade dos jovens, e também realizasse sistematicamente reuniões entre os professores e pais para a discussão das vivências e situações que estejam acontecendo, comunicando experiências, permitindo a reflexão e debate, aumentando as possibilidades de uma aprendizagem baseada no entendimento, no conhecimento científico, no compartilhamento de experiências.

A sexualidade é elemento importante na vida humana, entretanto ainda é cercada de mitos e preconceitos. Para resolver esta polêmica seria eficaz que a família possibilitasse espaços de interações com seus jovens sobre os múltiplos motivos, questões e assuntos que abrangem sexualidade, contudo nem sempre oportuniza abertura para que eles ocorram. Por conseguinte, se à família compete modelos de ética, respeito, moral, valores, à instituição escolar competirá conhecimentos científicos, programados, elaborados e organizados, constituindo-se como local adequado ao desenvolvimento da sexualidade, oportunizando a socialização de ideias, a convivência com as diversidades, as reflexões, as discussões, o diálogo e o trato com o contraditório, de forma respeitosa, positiva, adequada aos interesses e singularidades dos jovens.

Assim, como desdobramentos desta pesquisa, as autoras sugerem a inclusão no Projeto Político-Pedagógico da escola em que o estudo foi realizado, um projeto sobre "escola de responsáveis", para que os muitos assuntos que englobam a educação possam ganhar espaço no aprendizado dos familiares e na sua intervenção junto a seus filhos.

\section{REFERÊNCIAS}

ARIÈS, Philippe. História social da criança e da família. 2. ed. Rio de Janeiro: Zahar Editores, 1978. p. 11. BARROS, Suzana da Conceição de; RIBEIRO, Paula Regina Costa. Sexting, Sexcasting, revenge porn e nudes. Como a escola pode atuar nas discussões dessas práticas? Debates contemporâneos sobre educação para sexualidade. Organizadoras Paula Regina Costa Ribeiro e Joanalira Corpes Magalhães. Rio Grande: Editora da Furg, 2017. 
BARROSO, Carmen; BRUSCHINI, Maria Cristina. Educação sexual: debate aberto. São Paulo: Vozes, 1982. BRASIL. Estatuto da Criança e do Adolescente. Lei no 8.069, de 13 de julho de 1990. DOU de 16/7/1990 ECA. Brasília, DF: Câmara dos Deputados, 1990.

BRASIL. Ministério da Educação. Parâmetros Curriculares Nacionais para o Ensino Fundamental. Brasília: MEC; SEF, 1997. p. 291.

BRUNS, Maria Alves de T.; MELO, Sonia Maria M. (org.). Desafios da educação sexual: interfaces pertinentes com a comunicação e tecnologia. Curitiba: CRV, 2016.

CABRAL, Suzane Nascimento; SOUZA, Marcos Lopes de. Canalizar para o bem versus canalizar para o mal: uma leitura da disciplina Educação para a Sexualidade nos anos finais do Ensino Fundamental. Debates contemporâneos sobre educação para a sexualidade. Organizadoras Paula Regina Costa Ribeiro e Joanalira Corpes Magalhães. Rio Grande: Editora da Furg, 2017.

CARVALHO, Margarida Maria de. Caminhos e descaminhos percorridos por estudantes do 3o ano do Ensino Médio e portadores do vírus HIV, com relação às informações preventivas a respeito da AIDS. 2004. Dissertação (Mestrado) - Faculdade de Educação, Universidade de São Paulo, 2004.

DESSEN, Maria Auxiliadora; POLONIA, Ana da Costa. A família e a escola como contextos de desenvolvimento humano. Paidéia, Ribeirão Preto, [on-line], v. 17, n. 36, p. 22-25, 2007.

FERNANDES, Karina Nonato; REINA, Fabio Tadeu, WOKWA, Valéria M. N. F. A música na sala de aula: reflexões sobre sexualidade na educação básica. Revista Ibero-Americana de Estudos em Educação, Araraquara: Unesp, v. 10, 2015. ISSN 2446-8606.

FERNÁNDEZ, María Victoria Carrera; FERNÁNDEZ, María Lameiras; CASTRO, Yolanda Rodríguez. Intervención y evaluación de un programa de educación afectivo-sexual en la escuela para padres y madres de adolescentes. Universidad de Vigo, España, 2007. Disponível em: https://mail.google.com/mail/u/0/\#inbox?projector=1. Acesso em: 30 out. 2018.

FIGUEIRÓ, Mary Neide Damico. Educação sexual: em busca de mudanças. Londrina: UEL, 2009. 208 p.

FIGUEIRÓ, Mary Neide Damico. Homossexualidade e educação: construindo o respeito e a diversidade. Londrina: UEL, 2007. p. 28-129.

FRANCO, Maria Amélia do Rosário Santoro. Prática pedagógica e docência: um olhar a partir da epistemologia do conceito. Revista Brasileira de Estudos Pedagógicos, Brasília, v. 97, 2016. ISNN 0034-7183.

FURLANI, Jimena. Educação sexual na sala de aula: relações de gênero, orientação sexual e igualdade étnico-racial numa proposta de respeito às diferenças. Belo Horizonte: Autêntica Editora, 2011.

GOMES, Romeu. Análise de categorias. In: MINAYO, Maria Cecília de Souza (Org.). Pesquisa social: teoria, método e criatividade. 29. ed. Petrópolis, RJ: Vozes, 2009.

LOURO, Guacira Lopes. Gênero, sexualidade e educação: uma perspectiva pós-estruturalista. 16. ed. Petrópolis, RJ: Vozes, 2014.

MAIA, Ana Cláudia Bortolozzi; ARANHA, M. S. F. Relatos de professores sobre manifestações sexuais de alunos com deficiência no contexto escolar. Revista Interação, Curitiba, v. 9, n. 1, p. 103-116, 2005.

MAKSUD, Ivia. Sexualidade e mídia: discursos jornalísticos sobre o "sexual" e vida privada. Psicologia em Estudo, Maringá, v. 13, n. 4, p. 663-671, out./dez. 2008. Disponível em: http://www.scielo.br/pdf/pe/ v13n4/v13n4a04.pdf. Acesso em: 14 out. 2018.

MINAYO, Maria Cecília de Souza. O desafio do conhecimento: pesquisa qualitativa em saúde. 12. ed. São Paulo: Editora Hucitec, 2010. p. 16-77.

OLIVEIRA, Elisabete Regina Baptista de; VIANNA, Claudia. Educação e assexualidades: uma das dimensões da desigualdade no universo escolar. Debates contemporâneos sobre educação para sexualidade. Organizadoras Paula Regina Costa Ribeiro e Joanalira Corpes Magalhães. Rio Grande: Editora da Furg, 2017.

POSSAMAI, Leusa Fátima Lucatelli. Contribuições da pesquisa-ação na produção de conhecimentos escolares: experiências curriculares na rede pública municipal de educação de Chapecó (1997-2004). 2014. 240 f. Dissertação (Mestrado) - Universidade do Estado de Santa Catarina, Curso de História e Historiografia da Educação, Florianópolis, 2014. Disponível em: http://www.faed.udesc.br/arquivos/id_submenu/151/leusa_fatima_lucatelli_possamai.pdf. Acesso em: 9 dez. 2017.

RAUPP, Fabiano Maury; BEUREN, Ilse Maria. Metodologia da pesquisa aplicável às ciências sociais. In: BEUREN, I. M. (org.). Como elaborar trabalhos monográficos em contabilidade: teoria e prática. 3. ed. São Paulo: Atlas, 2006. p. 94-95. Cap. 3.

RODRIGUES, William Costa. Metodologia científica. Paracambi, RJ. Faetec; IST, 2007. p. 3. 
SZYMANSKI, Heloisa. Práticas educativas familiares: a família como foco de atenção psicoeducacional. Estud. Psicol., Campinas, on-line, v. 21, n. 2, p. 2, 2004. Disponível em: http://dx.doi.org/10.1590/S0103166X2004000200001. Acesso em: 23 nov. 2017.

VERGARA, Sylvia. Constant. Projetos e relatórios de pesquisa em administração. 3. ed. São Paulo: Atlas, 2000. p. 47.

WEREBE, Maria José Garcia. A educação sexual na escola. Lisboa: Moraes Editores, 1977. p. 149. 